\title{
Modelagem gravimétrica crustal 2-D utilizando informações a priori de perfis sísmicos e de geologia regional
}

\author{
*Gean Lucas Mello Farias (Universidade Federal Fluminense), Alexandre Motta Borges (Universidade Federal Fluminense)
}

Copyright 2016, SBGf - Sociedade Brasileira de Geofísica

Este texto foi preparado para a apresentação no VII Simpósio Brasileiro de Geofísica, Ouro Preto, 25 a 27 de outubro de 2016. Seu conteúdo foi revisado pelo Comitê Técnico do VII SimBGf, mas não necessariamente representa a opinião da SBGf ou de seus associados. É proibida a reprodução total ou parcial deste material para propósitos comerciais sem prévia autorização da SBGf.

\section{Resumo}

This work aimed to implement a cross-geological model to the shoreline, including the continent-ocean boundary, of the Pelotas Basin that is consistent with gravimetric data of the region. It will apply the results of interpretation of seismic sections and information taken from the regional geology literature in order to generate the required parameters to a inicial model, such as depth layers and densities.

\section{Introdução}

As investigações geofísicas desempenham um papel central na compreensão da Terra. Apesar da sísmica receber o maior montante de investimentos entre os métodos geofísicos, devido a sua importância na indústria petrolífera, a gravimetria também é importante para o estudo da geologia de subsuperfície, mostrandose algumas vezes como o método mais importante no mapeamento de estruturas da crosta praticamente inóspitas em relação ao sinal sísmico.

Um exemplo, tratado no presente trabalho, é a bacia de pelotas, onde a alta refletividade das vulcânicas dos seaward dipping reflectors depositados no rifte torna quase impeditivo o mapeamento da base do rifte em sísmicas tradicionais (Stica et al., 2009). Nestes casos, a gravimetria mostra-se como o método mais relevante no estudo da geologia crustal, contribuindo, desta forma, para o melhor entendimento das bacias sedimentares, até mesmo auxiliando na explicação do papel da geodinâmica na formação dos diversos tipos de bacias.

A base da gravimetria se encontra na interação gravitacional entre os corpos, cuja descrição analítica mais básica, considerando-se duas partículas de massas $\mathrm{M}$ e $\mathrm{m}$, encontra-se abaixo.

$$
F=\frac{G M m}{r^{2}}
$$

$\mathrm{Na}$ qual, $F$ é a força de interação entre os corpos, $G$ é a constante de gravitação universal e $r$ é a distância entre esses corpos.

Da mesma forma, encontra-se abaixo a equação da magnitude da aceleração gravitacional $g$ causada por uma partícula de massa $M$ a uma distância $r$ da partícula.

$$
g=\frac{G M}{r^{2}}
$$

Corpos geológicos, no entanto, devem ser tratados como distribuições contínuas de massa. O cálculo de sua influência gravitacional é um pouco mais complexo, sua demonstração será desprezada aqui.

$$
\vec{g}(Q)=-G \iiint_{P \in V} \rho(P) \frac{\overrightarrow{P Q}}{P Q^{3}} d V
$$

Neste caso, $Q$ é o ponto observado e $P$ é um ponto no corpo que localiza um elemento de volume $d V$.

Os gravímetros detectam a componente vertical do campo gravitacional. Deste modo a resposta gravimétrica do modelo deverá ser a derivada na direção vertical (Blakely, 1995).

A gravimetria também se mostra muito eficaz aplicado a outras informações independentes. A integração de dados provenientes de outros métodos geofísicos, além de dados da geologia local, diminui o efeito da ambiguidade inerente ao método geofísico trazendo resultados interpretativos mais plausíveis. O presente trabalho visou ao desenvolvimento de um modelo gravimétrico transversal à linha de costa da bacia de pelotas. $O$ método de modelagem escolhido foi 0 de modelagem direta, utilizando como dado de entrada o conhecimento prévio da geologia regional e dados provenientes de perfis sísmicos de reflexão.

\section{Metodologia}

A concepção do modelo direto envolve suposições acerca das características tais como a densidade, caso da gravimetria, da fonte dos dados geofísicos. O objetivo é ajustar o modelo aos dados observados em um processo iterativo de ajustes no modelo, que pode envolver condicionantes baseados em interpretações de dados provenientes de outros métodos, como a sísmica e a geologia conhecida, por exemplo.

Blakely (1995) apresenta a base do cálculo realizado pelas diferentes técnicas de modelagem sobre o modelo, dividindo-se o corpo geológico em $\mathrm{N}$ partes e assumindo a premissa da superposição:

$$
g_{m}=\sum_{n=1}^{N} \rho_{n} \psi_{m n}
$$


Onde $g_{m}$ é a atração vertical no m-ésimo ponto de observação, $\rho_{n}$ é a densidade da n-ésima parte do corpo, e $\psi_{m n}$ é a atração gravitacional no m-ésimo ponto de observação devido a n-ésima parte do corpo com densidade unitária cuja fórmula encontra-se a seguir.

$$
\psi(x, y, z)=-G \frac{z}{\left(x^{2}+y^{2}+z^{2}\right)^{3 / 2}}
$$

Os primeiros esforços do trabalho foram focados em elaborar um modelo prévio a ser ajustado no programa Oasis Montaj, mais precisamente, a extensão GM-SYS do programa. O GM-SYS permite criar modelos geológicos hipotéticos para calcular sua resposta gravimétrica e então comparar com o perfil gravimétrico do local de estudo, retirado dos dados da GETECH (Figura 1).

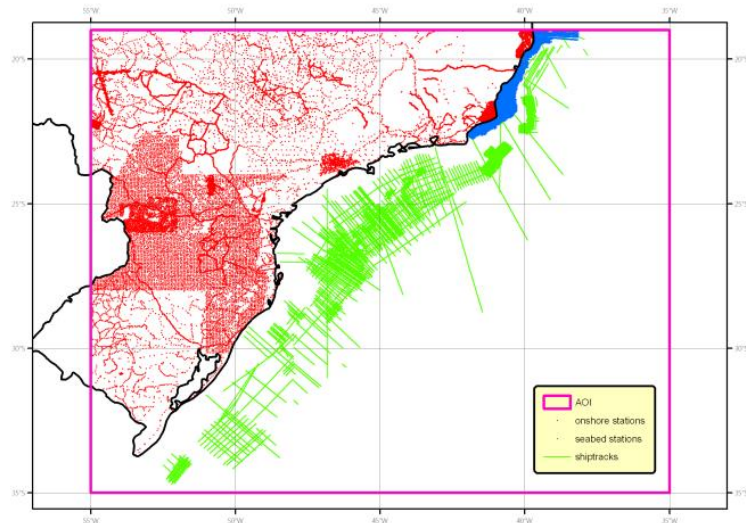

Figura 1 - Mapa mostrando a cobertura do grid de gravimetria, do qual será retirado o perfil gravimétrico, da GETECH, que integra dados de levantamentos marinhos, terrestres e de altimetria por satélite.

No presente trabalho, optou-se pela criação de um modelo 2-D, assumindo a Terra como sendo bidimensional, variando apenas com a profundidade (direção Z) e a direção do perfil (direção $X$, perpendicular ao strike). A NGA, 2004 ilustra que o modelo 2-D pode ser visto como construído por prismas que se estendem ao infinito na direção do strike (Figura 2).

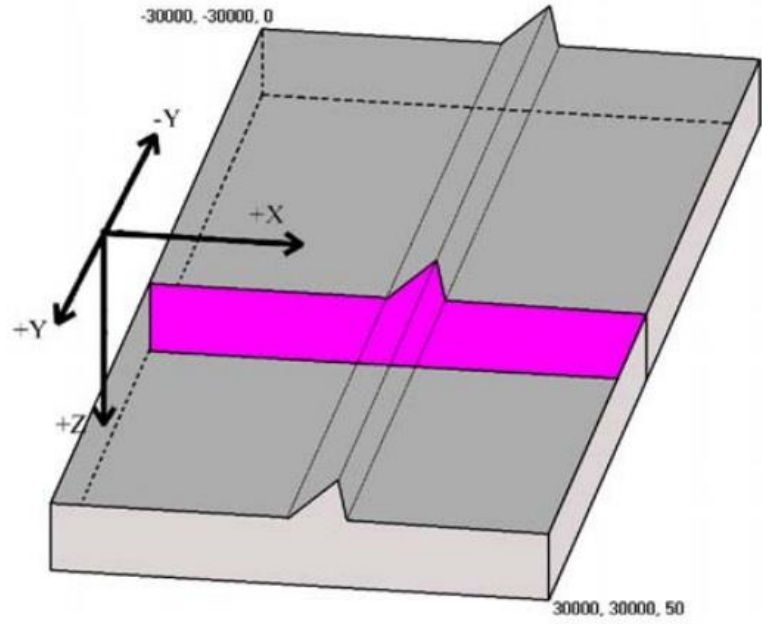

Figura 2 - Esquema simplificado de modelo 2-D visto como prismas que se estendem ao infinito na direção do strike (direção Y).

O cálculo da resposta gravimétrica do modelo no GMSYS é baseado nos algoritmos de Talwani et al., 1959 e Talwani and Heirtzler (1964, apud NGA, 2004) além de fazer uso de algoritmos descritos em Won and Bevis (1987, apud NGA, 2004). O modelo, no entanto, será construído a partir de um modelo inicial proveniente de dados de sísmica local 2-D e de conhecimentos da geologia regional. Os perfis utilizados no trabalho são da PETROBRÁS (Figura 3) e da LEPLAC (Figura 4), e coincidem com a localização do perfil gravimétrico.

\section{Resultados e Conclusões}

O principal resultado do trabalho será o modelo que descreve as principais expressões geológicas da Bacia de Pelotas e cuja resposta gravimétrica coincida com o perfil gravimétrico observado no local de estudo.

Espera-se que o modelo possa elucidar a localização da transição entre a crosta continental e oceânica; as localizações das principais formações da bacia, como as profundidades do topo e da base da fase rifte, além das profundidades da crosta continental superior e inferior, da crosta oceânica, do manto e do underplating, feição típica de margens passivas vulcânicas (Geoffroy, 2005).

\section{Agradecimentos}

É com gratidão que os autores lembram-se da GETECH, da Petrobrás e do projeto LEPLAC pelos dados utilizados no trabalho. O autor Gean Lucas também agradece ao Dr. Alexandre, por orientá-lo, ao Dr. Cleverson Guizan, o Dr. André Ferrari, e o Dr. Bruno Goutorbe por também terem ajudado ou inspirado o trabalho; além da SBGF pela oportunidade. 


\section{Referências}

Blakely R.J., 1995. Potential Theory in Gravity and Magnetic Applications. Cambridge University Press.

Geoffroy L., 2005. Volcanic passive margins. Comptes Rendus Geosci, 337, 1395-1408.

NGA., 2004. GM-SYS - Gravity/Magnetic modelling software user's guide. Corvallis: Northwest Geophysical Associate.
Stica J.M., Zalan P.L., Ferrari A.L., 2014. The evolution of rifting on the volcanic margin of the Pelotas Basin and the contextualization of the Paranáe Etendeka LIP in the separation of Gondwana in the South Atlantic. Marine and Petroleum Geology, 50: 1-21.

Talwani M., Worzel J. L., Landisman M., 1959. Rapid gravity computations for twodimensional bodies with application to the Mendocino Submarine Fracture Zone. Journal of Geophysical Research, 64: 49-59.

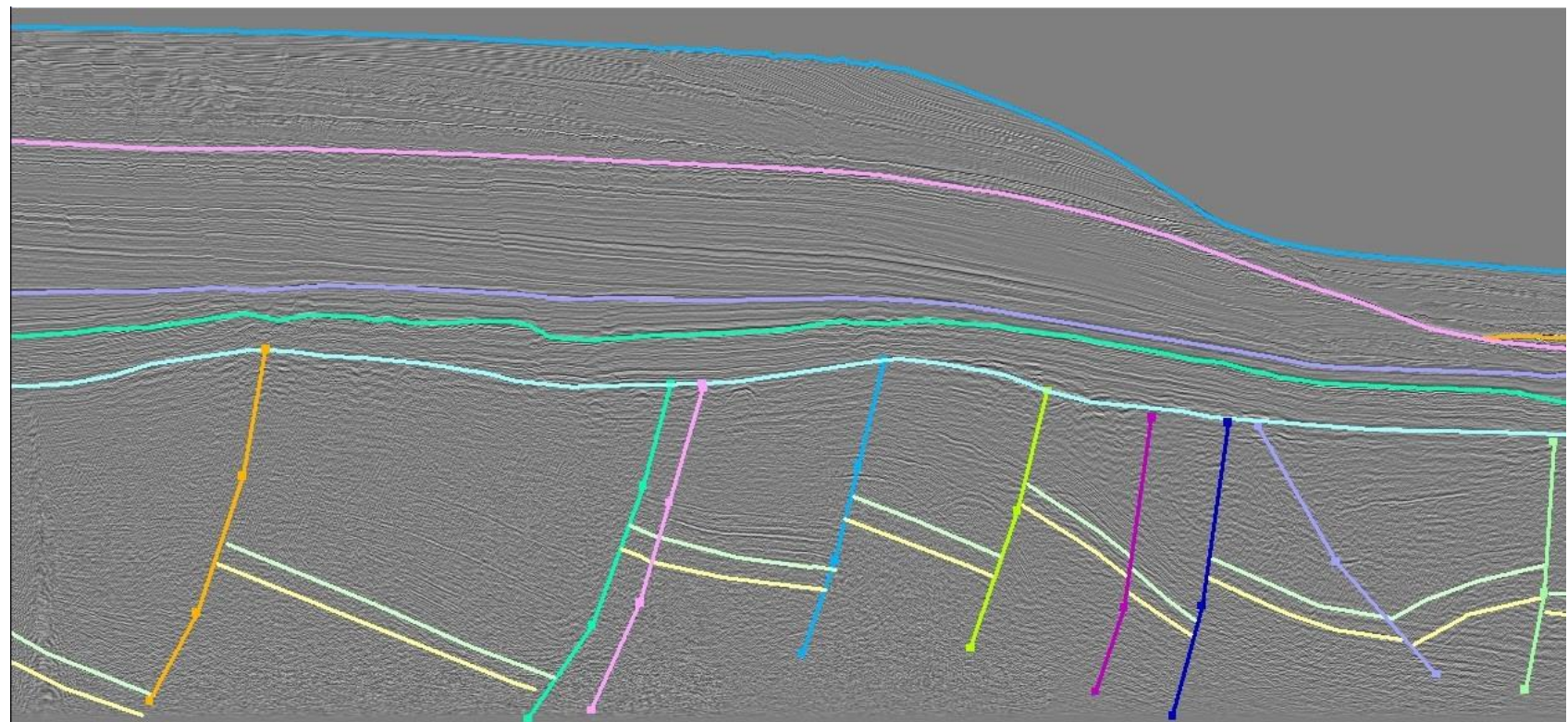

Figura 3 - Perfil sísmico da Petrobrás interpretado na região proximal da Bacia de Pelotas, ainda em domínio continental.

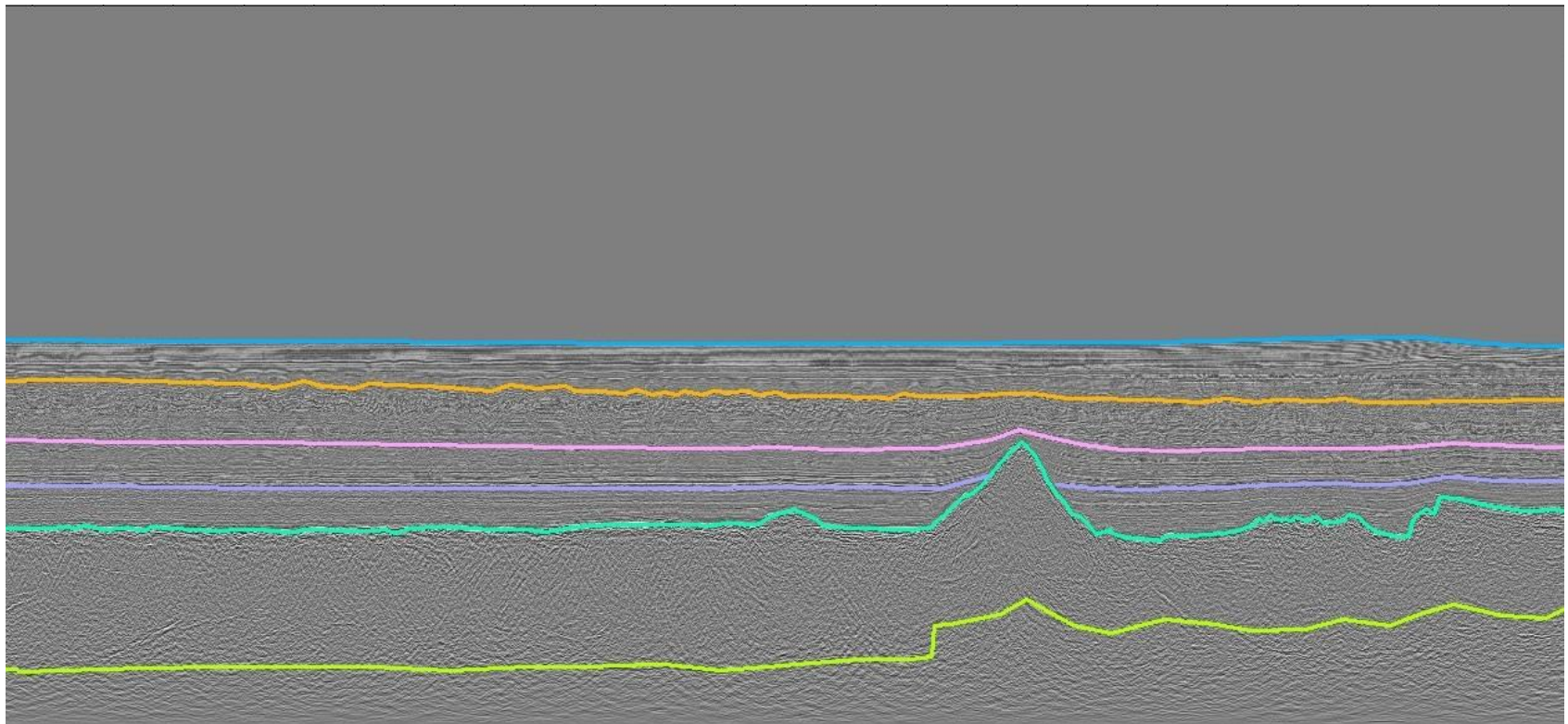

Figura 4 - Perfil sísmico do LEPLAC interpretado em domínio oceânico, região distal da Bacia de Pelotas. 